\title{
A Study on Evaluation and Influencing Factors of Carbon Emission Performance in China's New Energy Vehicle Enterprises
}

\section{Min Zhao ( $\sim$ hellen19822@163.com )}

Nanjing University of Aeronautics and Astronautics https://orcid.org/0000-0002-6288-9058

Tao Sun

Nanjing University of Aeronautics and Astronautics https://orcid.org/0000-0003-3121-2340

Qiang Feng

Nanjing University of Aeronautics and Astronautics

\section{Research Article}

Keywords: Carbon emission performance, Evaluation, Influencing Factors, New energy vehicle, SE-SBM model, STIRPAT model

Posted Date: March 19th, 2021

DOl: https://doi.org/10.21203/rs.3.rs-307576/v1

License: (c) (i) This work is licensed under a Creative Commons Attribution 4.0 International License. Read Full License 
1 A Study on Evaluation and Influencing Factors of Carbon Emission

2 Performance in China's New Energy Vehicle Enterprises

3 Min Zhao, Tao Sun*, Qiang Feng

Collage of Economics and Management, Nanjing University of Aeronautics and Astronautics, Nanjing, 21106, China

Abstract: Vehicle industry has made great contribution to human progress. However, in the process of vehicle operation, a large number of carbon compounds are emitted, which brings serious environmental problems. As one of the important means of vehicle carbon emission governance, the development of new energy vehicles(NEVs) has attracted much attention. The behavior and performance of NEV enterprises are highly concerned. Using Chinese 23 NEV vehicle enterprises' data from 2011 to 2018, this paper evaluates the carbon emission performance with the super-efficiency slacks-based measure (SE-SBM) model based on unexpected output, and then constructs STIRPAT model to analyze the influencing factors of carbon emission performance. The results indicate that, firstly, the carbon emission performance of China's NEV enterprises is not ideal at present, but it is increasing year by year. Secondly, the carbon emission performance of different NEV enterprise is distinct in the same year, and the carbon emission performance of the same NEV enterprise is distinct in different year. Thirdly, technological innovation, government support and free cash flow have NEV enterprises. significant positive impact on the carbon emission performance of NEV enterprises, while debt constraint, energy intensity and enterprise size have a significant negative impact on the carbon emission performance of

Key words: Carbon emission performance; Evaluation; Influencing Factors; New energy vehicle;

\footnotetext{
* Acknowledgements: This work has received funding from the general project of national social science foundation of China: "Research on mechanism and supportive polices of environmental pollution cooperative governance in the process of regional integration development of the Yangtze river delta" (Approval number: 19BJL035). The author thanks the National Office for philosophy and Social Sciences for this study support.

Authors: Min Zhao (1982-) ,Women Born in Suqian of Jiangsu province, doctor of management, School of Economics and Management, Nanjing University of Aeronautics and Astronautics. Research direction: Energy and environmental management; Tao Sun (1959-), Men, Born in Taian of Shandong province, Professor and doctoral supervisor of School of Economics and Management, Nanjing University of Aeronautics and Astronautics, Research direction: Environmental Finance. 
SE-SBM model; STIRPAT model 


\section{Introduction}

The development of vehicle industry has caused serious environmental problems. As we all know, road transportation is the main source of greenhouse gas emissions and air pollution (Bonsu, 2020). According to a recent study on Beijing, more than $80 \%$ of carbon compounds in the air come from vehicle emissions. For the survival and development of human beings, it is imperative to reduce the carbon emissions in the process of vehicle operation. Due to the strong mobility of vehicle operation, the exhaust gas purification technology has little effect. Vehicle carbon emission governance must be considered from the source of production. However, considering the importance of vehicle industry to human society, all countries in the world can't give up developing vehicle industry. Developing new energy vehicle (NEV) becomes the preferred strategy for countries to realize low-carbon economic development of vehicle industry (Rehermann et al., 2018).

The view that NEVs can effectively reduce vehicle carbon emissions by replacing traditional vehicles supported by many scholars at home and abroad. DeLuehi et al. (1989) concluded that new energy pure electric vehicles have great advantages in emission reduction, through the analysis of the emission reduction effect of new energy pure electric vehicles, in the 1990s. Thereafter, a large number of scholars have compared and analyzed the carbon emissions in the process of use between electric vehicles and traditional vehicles. These studies concluded that the development of new energy electric vehicles can achieve emission reduction(Lucas et al.,2012; Zhai et al., 2011; Thiel et al.,2010; Doucette et al., 2011; Delucchi et al., 2014). A survey of NEV projects in Beijing and Shenzhen, China, shows that the large-scale promotion of NEVs is of strategic significance to China's climate change and urban air quality(Bank, 2011). In recent years, countries all over the world are actively promoting NEVs to effectively reduce carbon emissions in the process of driving (Glitman et al., 2019). The research on the carbon emission reduction effect of NEVs in the world is more in-depth and extensive. A research in Taiwan, China, found that the promotion and use of NEVs can effectively reduce carbon emissions ( $\mathrm{Li}$ et al., 2016). The evaluation of the impact of replacing traditional vehicles with 
electric vehicles on carbon emissions in Brazil under different scenarios shows that even considering the most

45 unfavorable power generation situation, the carbon emissions of electric vehicles are 10 times lower than that of traditional vehicles (Teixeira et al., 2016). Some scholars (Jenn et al., 2018; Shaheen et al., 2019) found that the extensive use of NEVs in the United States is an effective means to reduce carbon emissions. A research on carbon emission of electric vehicles in Saudi Arabia simulated different scenarios of electric vehicle use, and tested carbon emissions in the best and worst scenarios of each scenario. The test results show that for every $1 \%$ of electric vehicles deployed, carbon emissions will be reduced by $0.5 \%$, while in the best case, the deployment of $1 \%$ electric vehicles will reduce carbon emissions by $0.9 \%$ (Elshurafa et al., 2020). Choi et al. (2020) measured the carbon emission intensity of various internal combustion engine vehicles and NEVs in South Korea. The measurement results showed that the carbon emission of various NEVs was lower than that of internal combustion engine vehicles. A study in Ghana found that a traditional vehicle emitted 3.35 times more $\mathrm{CO}_{2}$ than an electric vehicle (Ayetor et al., 2020) .

The low-carbon emission characteristics of NEVs make it a popular choice to govern vehicle carbon emissions, but whether it can develop well depends on its economic benefits (Feng, 2020). The vehicle carbon emission governance is not simply to reduce carbon emissions, but to carry out environmental governance and industry development simultaneously. As one of the emerging industries, the NEV project will experience a long process from the proposal, successful research and development to the market. As a result, the project of NEV inevitably has high uncertainty (Claude, 2003). The existence of uncertainty leads to the low income of $\mathrm{NEV}$ project. If the manufacturer produces NEVs, the carbon emission of the vehicles will be reduced, but the financial performance is likely to be not optimistic (Juan, 2011). In the survey on low-carbon transportation, electric vehicle expectation and prospect (Sovacoola et al., 2019), many experts pointed out that the R\&D of NEVs will lead to greater financial difficulties and even bankruptcy due to insolvency. Therefore, without the government's incentive or mandatory policies, developing NEV industry may face greater difficulties $(\mathrm{Li}$, 

this case, vehicle carbon emissions will increase. To achieve the goal of low-carbon development of vehicle industry, it is very important to guide manufacturers to carry out vehicle carbon emission governance activities spontaneously. Evaluating the carbon emission performance of NEV enterprises and studying the influencing factors can provide reference for the government to formulate policies to guide vehicle enterprises to carry out carbon emission reduction governance activities.

For a long time, there are many literatures on carbon emission performance, and the evaluation methods of carbon emission performance are different. Early studies were conducted from a single factor perspective. The researchers defined carbon emission performance in a single factor framework. For example, carbon emission performance is measured by the ratio of total $\mathrm{CO}_{2}$ emissions to GDP. Although this method is easy to operate and understand, it fails to take other factors into account. Therefore, the results are not accurate enough. Then, some scholars proposed to define $\mathrm{CO}_{2}$ emission performance under the framework of total factors, considering the comprehensiveness and scientificity of factor input. The methods used include stochastic frontier approach(SFA)(Wang, 2019) and data envelopment analysis(DEA)(Reinhard et al., 2000; Guo et al., 2011; Shuai et al., 2020). The key to measure carbon emission performance from the perspective of total factors is to determine the production frontier boundary. The application of SFA method needs to define the stochastic frontier production function in advance, which is usually difficult to determine. Therefore, there are more researches on evaluating carbon emission performance by nonparametric frontier method based on DEA model. DEA method is more objective and comprehensive. Environmental externalities and other factors can be considered as a production in DEA. On the basis of the original model, many scholars continue to expand and innovate the evaluation methods by improving the model form and introducing variable indicators. A set of 
cannot solve the "slack" problem of input and output elements of decision-making units. In order to solve this

91 problem, Tone constructed slack based measure (SBM) model(Tone, 2001) and super-efficiency slack-based measure (SE-SBM) model(Tone, 2002), by directly introducing the input and output slack into the planning model. Different from the traditional performance measurement, the quantity of carbon emission in carbon emission performance measurement is a kind of output that the smaller the better. In order to solve the performance measurement problem of output index with the smaller the better, Tone (2004) proposed SBM models considering the unexpected output on the basis of SBM. In recent years, a series of SBM models are the mainstream models to measure carbon emission performance. These models are not only used to measure the carbon emission performance of industries and regions (Zhou et al., 2019; Lin et al., 2019; Yan et al., 2017; Wanga et al., 2019; Wang, 2020; Chang, 2020), but also used to evaluate the carbon emission performance and environmental performance of enterprises(Wang et al., 2019; Cecchini et al., 2018; Chang et al., 2014; Kang et al., 2016). problems to be solved. Firstly, most of the existing studies are focused on the effect of carbon emission governance of NEVs, while few studies are focused on the behavior of NEV manufacturers. According to the theory of sustainable development, the goal of carbon emission reduction should ensure the coordinated development of economy, environment and energy, rather than simply reducing the total amount of carbon emissions. In fact, as vehicle production department, the behavior of enterprises has a crucial impact on vehicle carbon emission reduction, which must be paid much attention to. Secondly, there is a lack of research on carbon emission performance evaluation of NEV manufacturers. Some of the existing studies focus on the issue of vehicle carbon emission reduction, some on the issue of enterprise financial performance, and few studies combine the two. In fact, only the carbon emission performance combined by vehicle carbon emission and enterprise financial performance is the key indicator to judge whether NEVs can promote social green 
113 development. After all, the ultimate goal of vehicle carbon emission governance should be to pursue the

114 symbiosis of vehicle industry development and environmental governance. Only the carbon emission 115 governance effect evaluation of NEVs based on the carbon emission performance has practical significance.

116 According to the carbon emission performance evaluation results, the government can timely adjust the NEV

117 industry policy and environmental governance policy, which can guide the NEV manufacturers to adjust their

118 behavior to achieve the goal of ecological civilization and sustainable development. Thirdly, What factors

119 affect the carbon emission performance of NEV enterprises? The retrieved literatures have not been involved,

120 although the problem is worth studying. Analyzing the influencing factors of carbon emission performance of

121 NEV enterprises and improving the carbon emission performance starting from these influencing factors are of

122 great significance to improve the effect of vehicle carbon emission governance. Based on the above analysis,

123 starting from the actual needs of vehicle carbon emission governance and sustainable development of NEV

124 industry, this paper first uses SE-SBM model based on unexpected output to evaluate the carbon emission

125 performance of Chinese NEV enterprises, and then constructs STIRPAT to analyze the influencing factors of

126 carbon emission performance of NEV enterprises in complex environment, hoping to provide a new

127 perspective for the governance of vehicle carbon emission reduction from the micro perspective.

128 The research framework of this paper is shown in Fig. 1. Firstly, we use the SE-SBM model based on

129 unexpected output to evaluate the carbon emission performance of NEV enterprises in China from 2011 to

130 2018. Then, we build STIRPAT model to analyze the influencing factors of carbon emission performance of

131 NEV enterprises. Finally, we analyze the influence mechanism of influencing factors on carbon emission performance of NEV enterprises and put forward suggestions. 


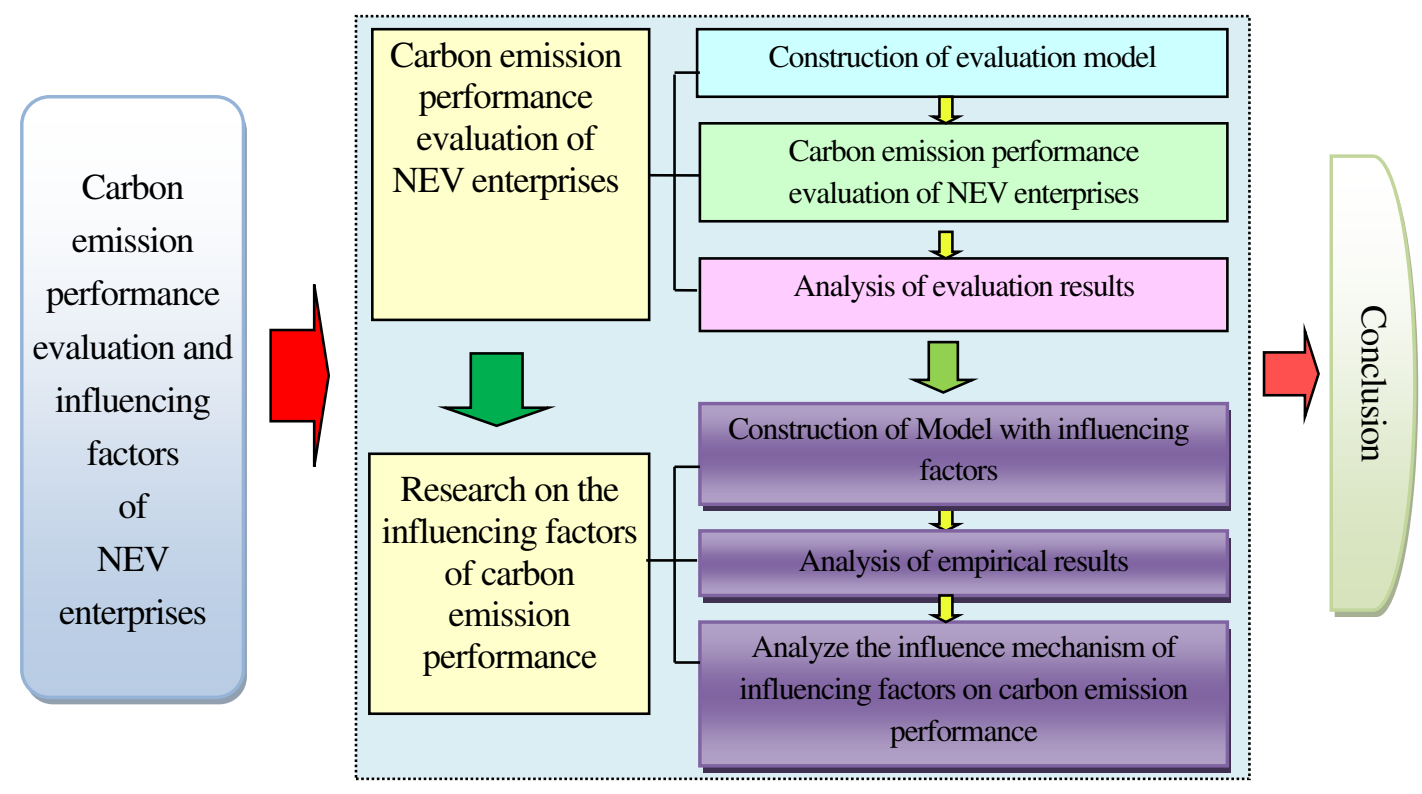

133

Fig. 1 Research framework

\section{Carbon emission performance evaluation of NEV enterprises}

\subsection{Method}

The SBM model proposed by Tone solves the slack of input factors and output in traditional DEA model.

It is suitable for the analysis of complex production process with multi input and multi output. However, the

model ignores the simultaneous existence of expected output and unexpected output in the production process,

which may affect the accuracy of the results. Later, Tone improved the previous SBM model. By separating expected output from unexpected output, he proposed a SBM model based on unexpected output:

$$
\begin{gathered}
\min \rho=\frac{1-(1 / m) \sum_{i=1}^{m}\left(s_{i 0}^{-} / x_{i 0}\right)}{1+\frac{1}{n_{1}+n_{2}}\left[\sum_{r g=1}^{n_{1}}\left(s_{r 0}^{g+} / y_{r 0}^{g}\right)+\sum_{r^{b}=1}^{n_{2}}\left(s_{r 0}^{b-} / y_{r 0}^{b}\right)\right]} \\
\left\{\begin{array}{c}
x_{i 0}=\sum_{j=1}^{Z} x_{i j} \lambda_{j}+s_{i}^{-}, \quad i=1,2, \ldots, m \\
y_{r 0}^{g}=\sum_{j=1}^{Z} y_{r j}^{g} \lambda_{j}-s_{r}^{g+}, \quad r=1,2, \ldots, n_{1} \\
y_{r 0}^{b}=\sum_{j=1}^{Z} y_{r j}^{b} \lambda_{j}+s_{r}^{b-}, \quad r=1,2, \ldots, n_{2} \\
s_{i}^{-} \geq 0, s_{r}^{g+} \geq 0, \quad s_{r}^{b-} \geq 0, \quad \lambda_{j} \geq 0, \quad \sum_{j=1}^{Z} \lambda_{j}=1
\end{array}\right.
\end{gathered}
$$

In the formula, $m$ is the sorts of input elements; $n_{1}$ is the sorts of expected output; $n_{2}$ is the sorts of unexpected output; $z$ is the number of decision-making units; $i$ is the input of type $i ; r$ is the output of type $r$. The superscript $g, b$ is the expected and unexpected; $j$ is the $j$-th decision-making unit; $x_{i 0}, y_{r 0}^{g}$, $y_{r 0}^{b}, s_{i}^{-}, s_{r}^{g+}, s_{r}^{b-}$ are input, expected output, unexpected output, input relaxation, expected output 
relaxation and unexpected output relaxation; $\lambda_{j}$ is a set of column vectors, representing the weight of each

$[0,1]$. The DMU satisfying the condition of $\rho=1$ and $s^{-}=0, s^{g+}=0, s^{b-}=0$ is valid, otherwise the DMU is invalid. It is necessary to adjust the input or output to achieve the effectiveness. Equation (1) is SBM model based on variable returns to scale of production system. If the condition $\sum_{j=1}^{z} \lambda_{j}=1$ is removed, the SBM model based on constant returns to scale can be obtained.

The SBM model based on non expected output can solve the problem of performance evaluation of production process with expected output and unexpected output simultaneously. However, there is still a defect in the application of SBM model in performance evaluation, that is, it is unable to grade and rank multiple decision-making units which are effective at the same time. In order to solve this problem, Tone continued to

follows:

calculates the carbon emission performance of NEV enterprises with the formula (2).

\subsection{Variables and data}

In July 2011, the Chinese government held a summary meeting on the promotion of NEVs in Beijing, 
169 the infrastructure construction has been steadily promoted. Since then, NEVs have entered a state of steady

170 development. Considering the availability of data and the representativeness of research samples, this paper

171 selects the listed enterprises of NEVs as the research object, and 2011-2018 as the research period. The data in

172 this paper are from CSMAR database, Wilson Dashi database, cninfo.com, annual reports of listed enterprises

173 and official websites. Some missing data are sorted out manually. SBM method has a high demand for data.

174 The input data must be positive. In this paper, for some enterprises whose output data is negative, the output

175 number is replaced by a small positive number. In this way, the software can be analyzed normally and the

176 effect will not be affected. The statistical software is matlab2016a.

It is necessary to select appropriate input and output indicators to measure the carbon emission

performance of NEV enterprises using SE-SBM. Referring to the research on carbon emission performance at

home and abroad, in order to describe the input situation from multiple perspectives, this paper selects three

indicators, namely, the stock of net assets, the number of employees and vehicle energy input, as input

indicators. Net assets are measured by the average annual owner's equity of the enterprise. The number of

employees is measured by the average number of employees in the enterprise. Energy input refers to the total energy consumption of all driving mileage in the life cycle of annual sales vehicles converted into the quantity of standard coal.

The goal of vehicle carbon emission reduction should be the coordinated development of environmental governance and enterprise sustainable operation. Therefore, the determination of output indicators should not only focus on carbon emission reduction, but also on business performance of enterprise. This paper chooses the common achievements which can represent the vehicle emission reduction activities and business performance to measure the achievement of vehicle emission reduction targets. The output indicators are divided into expected output and unexpected output. The main function of expected output index is to measure the operating performance of NEV enterprises. We choose the main business profit, net profit, main business 
profit growth, net profit growth, patents and vehicle sales of NEV manufacturers to represent the expected output. The main business profit reflects the main business profit of the enterprise. The net profit reflects the overall profit situation of the enterprise. The growth of the profit of the main business and the increase of the net profit reflect the growth of the financial performance of the enterprise. The patents reflects the innovation ability of the enterprise. The vehicle sales reflects the market share of the enterprise products. The non expected output index is the quantity of carbon emission, which is the embodiment of vehicle carbon emission status. This paper estimates the amount of carbon emissions by IPCC(2006) inventory method. The specific formula is as follows:

$$
\left(\mathrm{co}_{2}\right)_{j t}=\sum_{j=1}^{n} E_{j t} \times \partial_{j} \times \gamma_{j} \times \theta_{j} \times \frac{44}{12}
$$

In the formula(3), $E_{j t}$ denotes the energy consumption all over the life cycle of all the $j$-th type of vehicle sold in the t-th year. $\partial_{j}$ denotes the low calorific value of energy consumed by the $\mathrm{j}$-th vehicle. $\gamma_{j}$ is the carbon content of energy consumed by the $\mathrm{j}$-th vehicle. $\theta_{j}$ is the carbon oxidation factor of energy consumed

by the $\mathrm{j}$-th vehicle. $\frac{44}{12}$ denotes that the molecular weight of carbon is 12 and that of carbon dioxide is 44 , which means that a ton of carbon can produce about 3.67 tons of carbon dioxide after burning in oxygen.

According to existing research, the dimension difference of input-output indexes will not affect the SBM calculation results. However, in order to better analyze the decision-making unit, this paper uses the threshold method to process the original data dimensionless. After processing, the value of each index is between $0-1$.

The processing method is as follows:

For input indicators, the smaller the value, the better. Let $y_{i j}=(1-\alpha)+\alpha \times \frac{x_{\max (j)-x_{i j}}}{x_{\max (j)}-x_{\min (j)}}$ For output indicators, the higher the value, the better. Let $y_{i j}=(1-\alpha)+\alpha \times \frac{x_{i j}-x_{\min (j)}}{x_{\max (j)}-x_{\min (j)}}$

\subsection{Results and analysis}

With the SE-SBM model based on unexpected output, this paper uses matlab2016a software to calculate the carbon emission performance of NEV enterprises in 2011-2018 and make descriptive statistics on the 
215 calculation results. The calculation results and descriptive statistics are shown in Table 1.

Table 1 Carbon emission performance of NEV enterprises in 2011-2018

\begin{tabular}{|c|c|c|c|c|c|c|c|c|}
\hline$\overbrace{\text { Enterprise }}^{\text {Year }}$ & 2011 & 2012 & 2013 & 2014 & 2015 & 2016 & 2017 & 2018 \\
\hline BYD & 0.401 & 0.576 & 0.650 & 1.000 & 1.087 & 1.050 & 1.315 & 1.309 \\
\hline GEELY & 0.495 & 0.486 & 0.537 & 0.788 & 0.816 & 0.911 & 0.993 & 1.106 \\
\hline BEIJING & 0.437 & 0.471 & 0.516 & 0.693 & 1.034 & 1.165 & 1.103 & 1.000 \\
\hline GAC GROUP & 0.591 & 0.679 & 0.635 & 0.746 & 0.881 & 0.943 & 0.903 & 0.976 \\
\hline SAIC GROUP & 0.618 & 0.765 & 0.873 & 0.865 & 0.879 & 0.864 & 0.914 & 0.962 \\
\hline CHANGAN & 0.493 & 0.539 & 0.669 & 0.797 & 0.761 & 0.798 & 0.876 & 0.869 \\
\hline CHANGCHENG & 0.414 & 0.499 & 0.643 & 0.654 & 0.797 & 0.805 & 0.899 & 0.887 \\
\hline YUTONG & 0.649 & 0.697 & 0.709 & 0.834 & 0.931 & 0.963 & 1.000 & 0.953 \\
\hline JAC GROUP & 0.568 & 0.573 & 0.671 & 0.737 & 0.811 & 0.761 & 0.817 & 0.748 \\
\hline DONGFENG & 0.374 & 0.408 & 0.478 & 0.766 & 0.843 & 0.934 & 0.865 & 0.861 \\
\hline KING-LONG & 0.231 & 0.419 & 0.465 & 0.614 & 0.694 & 0.913 & 0.836 & 0.830 \\
\hline $\mathrm{JMC}$ & 0.581 & 0.617 & 0.682 & 0.659 & 0.820 & 0.839 & 0.795 & 0.930 \\
\hline ASIASTAR & 0.617 & 0.589 & 0.696 & 0.775 & 0.713 & 0.804 & 0.826 & 0.913 \\
\hline ZHONGTONG & 0.415 & 0.487 & 0.651 & 0.647 & 0.705 & 0.798 & 0.833 & 0.846 \\
\hline CHERY & 0.301 & 0.276 & 0.314 & 0.403 & 0.475 & 0.632 & 0.583 & 0.674 \\
\hline JIEFANG & 0.287 & 0.395 & 0.398 & 0.439 & 0.597 & 0.563 & 0.709 & 0.676 \\
\hline CAMC & 0.331 & 0.473 & 0.599 & 0.715 & 0.795 & 0.766 & 0.816 & 0.787 \\
\hline SG & 0.413 & 0.606 & 0.735 & 0.789 & 0.891 & 0.815 & 0.763 & 0.817 \\
\hline SOKON & 0.461 & 0.415 & 0.574 & 0.764 & 0.791 & 0.697 & 0.877 & 0.849 \\
\hline AK & 0.318 & 0.451 & 0.719 & 0.720 & 0.731 & 0.763 & 0.795 & 0.507 \\
\hline FOTON & 0.384 & 0.396 & 0.477 & 0.563 & 0.682 & 0.513 & 0.519 & 0.911 \\
\hline HAIMA & 0.591 & 0.683 & 0.832 & 0.687 & 0.781 & 0.869 & 0.701 & 0.613 \\
\hline XIALI & 0.565 & 0.539 & 0.643 & 0.705 & 0.816 & 0.697 & 0.785 & 0.530 \\
\hline Mean & 0.458 & 0.523 & 0.616 & 0.711 & 0.797 & 0.820 & 0.849 & 0.850 \\
\hline Median & 0.437 & 0.499 & 0.643 & 0.72 & 0.797 & 0.805 & 0.833 & 0.861 \\
\hline Max. & 0.649 & 0.765 & 0.873 & 1.000 & 1.087 & 1.165 & 1.315 & 1.309 \\
\hline Min. & 0.231 & 0.276 & 0.398 & 0.403 & 0.475 & 0.513 & 0.519 & 0.507 \\
\hline Std. & 0.119 & 0.116 & 0.129 & 0.126 & 0.127 & 0.144 & 0.159 & 0.175 \\
\hline
\end{tabular}

218 The results show that, from 2011 to 2018, the mean and median of NEV enterprises' carbon emission

219 performance increased from 0.458 and 0.437 to 0.850 and 0.861 respectively, showing a continuous increasing

220 trend. The Max. and Min. are also growing (Fig. 2). This shows that in terms of technology, the carbon

221 emission governance effect of NEVs is gradually improving, and in terms of scale, the environmental

222 governance role of NEVs is also gradually expanding the impact. This is in line with the development 
expectation of NEVs(Liu et al., 2020). In recent years, subject to the pressure of environmental governance, the

224 global NEVs are in a period of rapid development. The development momentum of China's NEV industry is more powerful. Chinese government attaches great importance to the development of NEVs. With the gradual implementation of the sustainable development strategy to promote ecological civilization, the Chinese 227 government has issued a number of favorable policies to support the sustainable development of NEVs. For example, in 2010, the NEV subsidy policy was introduced, and infrastructure construction also accelerated. In 2012, China announced the exemption of vehicle and vessel tax for NEVs. In 2014, four ministries and commissions including the Ministry of Finance jointly formulated the policy of increasing the subsidy standards for NEVs in 2014 and 2015. In the same year, the executive meeting of the State Council clearly stated that the purchase tax of NEVs would be continuously exempted. These policies not only encourage NEV enterprises to improve vehicle performance and increase market share through technological innovation, but also guide consumers to purchase NEVs instead of traditional vehicles, which greatly reduces carbon emissions while ensuring vehicle enterprises to improve performance. Inspired by a series of policies, NEV manufacturers expand the global view of the industry. They not only closely cooperate with upstream and downstream enterprises, but also make a series of adjustments within the enterprise. They improve the quality of R\&D personnel, establish a high-level $R \& D$ team, and even have $R \& D$ personnel in the sales team to promote R\&D achievements. These measures not only effectively improved the level of technological innovation and accelerated the transformation speed of technological achievements, but also speed up the popularization and application of new technologies in the industry. Technological progress has greatly improved the carbon emission performance of NEV enterprises, and made contributions to the governance of vehicle carbon emissions. However, the calculation results also show that the carbon emission performance mean of NEV enterprises from 2011 to 2018 is always less than 1, which is in the invalid state of data envelopment analysis. Even in 2018 with the highest average, the carbon emission performance is only 0.850 . 
There is still room for improvement of about $15 \%$. This means that NEV enterprises have great potential in

247 improving carbon emission performance. The selected samples are listed enterprises, representing the high-quality part of the vehicle enterprises. It means that the whole industry of NEV still has a lot of room for improvement in emission reduction and efficiency. The unsatisfactory carbon emission performance of NEV enterprises indicates that developing NEV industry needs the cooperation of policies and the whole industry chain. Enterprises must take the initiative. Perhaps this is why China has changed its policy direction in recent years. The government is impelling vehicle enterprises to strengthen the technological innovation of NEVs by administrative means and market forces instead of simply issuing preferential policies.

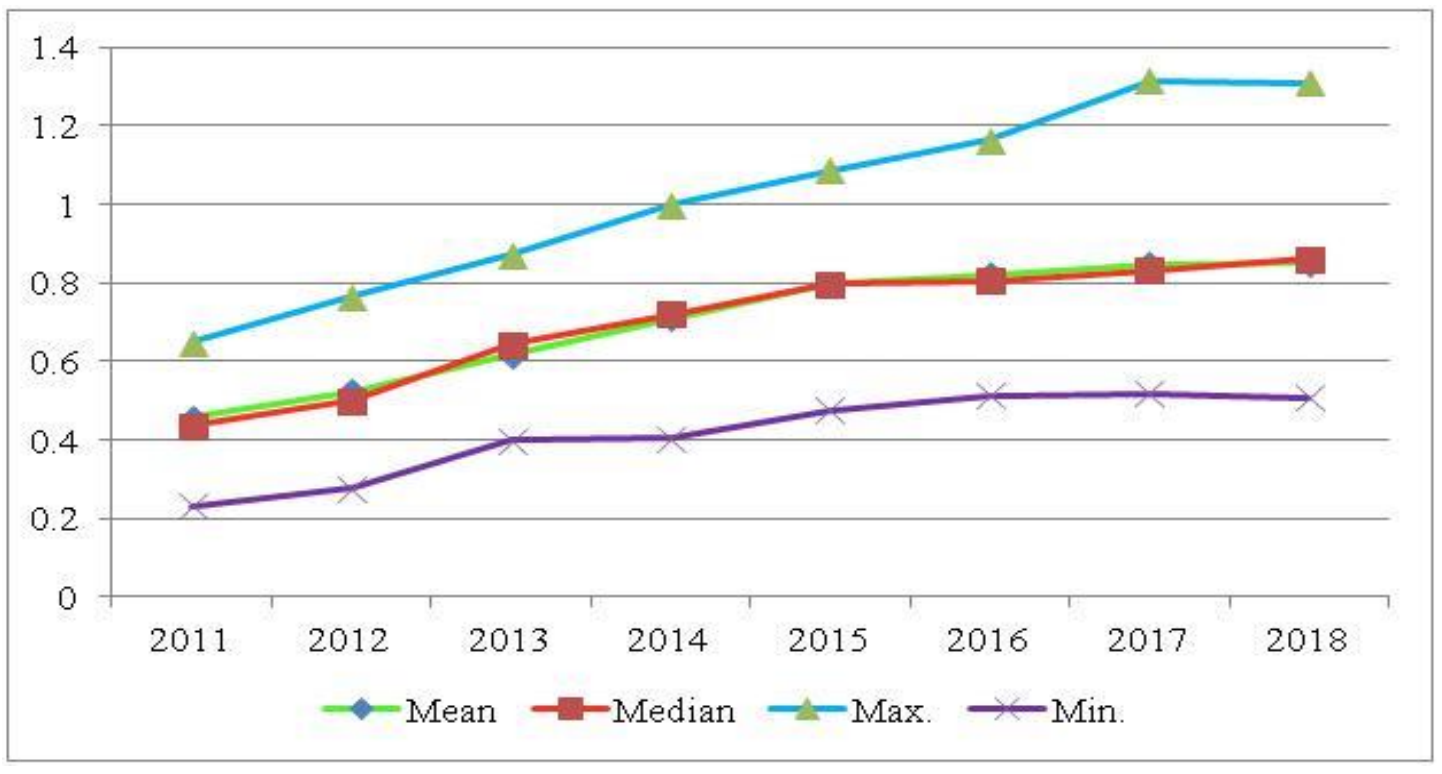

Fig.2 Carbon emission performance trends of NEV enterprises from 2011 to 2018

Different NEV enterprises have distinct carbon emission performance in the same year, and the same NEV enterprise has distinct carbon emission performance in different years. From 2011 to 2018 , the carbon emission performance of listed enterprises of NEVs has a certain Std., which indicates that the carbon emission performance of different NEV manufacturers is different. From the numerical point of view, with the passage of time, the difference has a tendency to expand gradually (Fig.3). Through further analysis of relevant data, it is found that this is closely related to government support, enterprise development concept and enterprise technology level. At the initial stage, NEV enterprises have obtained a certain degree of 

stage is mainly due to the unreasonable goals set in the process of technology optimization and upgrading.

Many innovative activities of some enterprises are to obtain financial support from the government. They do not fully consider the market demand, so their adaptability to the market is weak. Coupled with the long industrialization cycle, their innovation achievements are seriously adversely affected, resulting in the inefficient use of input resources. NEV listed enterprises represent the high-quality part of the industry. It can be inferred that there should be a certain number of enterprises in the NEV industry with these problems.

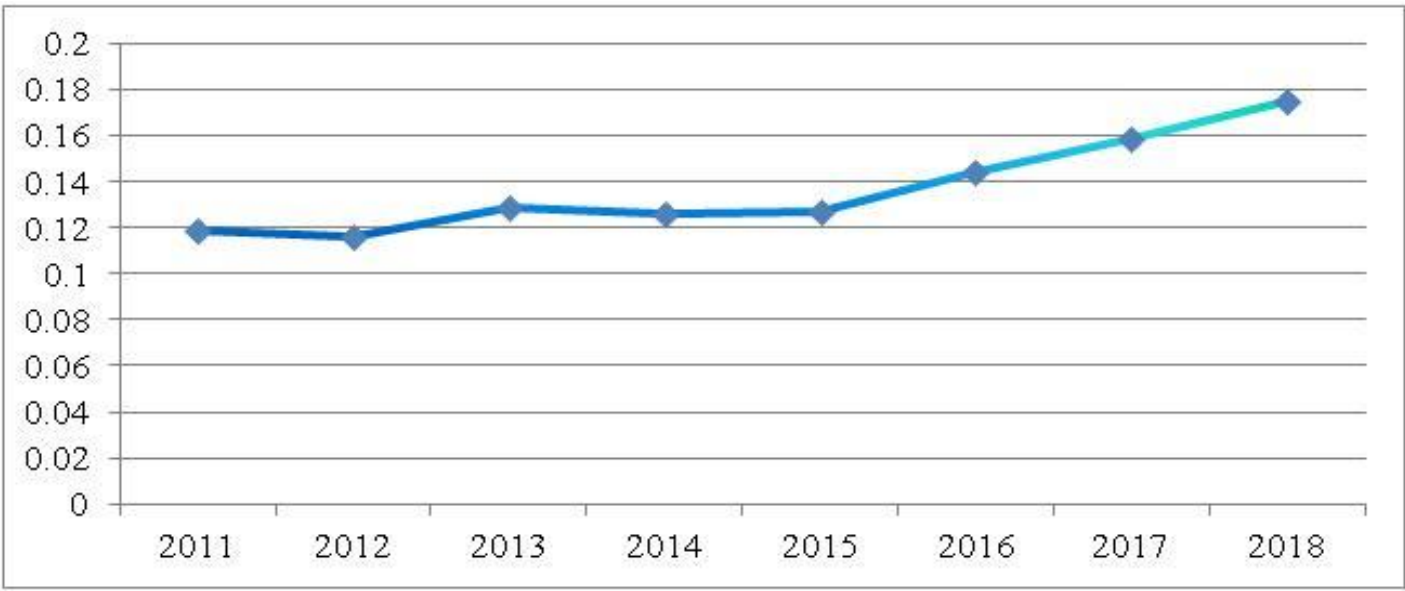

Fig. 3 Trend of carbon emission performance Std. between NEV enterprises from 2011 to 2018

By comparing the data of the same NEV enterprise in different years, we find that the carbon emission performance mean shows an increasing trend (Fig. 4). Through further investigation, we can see that the carbon emission performance of most vehicle enterprises has increased to a large extent before and after 2015. According to the data, since 2014, the Chinese government's support policy for the NEV industry is stronger than in previous years, which has greatly stimulated the development of the NEV industry. For example, BYD's sales of NEVs have been ranked first in the world for four consecutive years since 2016. This finding shows that the development of NEVs is an effective means to reduce carbon emissions and improve environmental conditions (Elshurafa et al., 2020; Ayetor et al., 2020). Traditional vehicle environmental load mainly comes from vehicle exhaust, which is mainly from the compounds produced by fuel. The main power 

carbon emissions in the process of coal combustion, these carbon compounds are much less than those of fuel vehicles. This shows that the sustainable development ability of NEVs is better than that of traditional vehicles. governance. If the vehicle enterprises speed up the R\&D of clean energy and increase the proportion of clean energy use, the effect of NEVs on improving carbon emission governance will be more significant. This may traditional energy, and advocate the use of NEVs to replace traditional vehicles.

\section{Research on influencing factors of carbon emission performance in NEV enterprises}

\subsection{Influencing factors and variables}

On the basis of the previous research, this part further discusses the influencing factors of carbon emission

performance of NEV enterprises by constructing panel data STIRPAT model. 
issued by the government have a greater incentive effect on production enterprises and vehicle carbon emission reduction (Li, 2020; Wu et al., 2021). Free cash flow, debt constraint, energy intensity, and enterprise size also have important effects on enterprise financial performance and vehicle carbon emissions (Cui et al., 2021; Braune et al., 2020; Han et al., 2019).

Therefore, this paper mainly selects the following factors to research: technological innovation(TI), government support(G), relative free cash flow(FCF), debt constraint(ALR), energy intensity(ENERGY) and enterprise size(LSA). We take the above six factors as explanatory variables of the model. The TI is measured by the ratio of patents to $R \& D$ personnel input. $G$ is divided into direct support (GD) such as monetary subsidies and indirect support (GI) such as preferential tax policies. GD is measured by government subsidies/operating income. GI is measured by the ratio of the NEV industry support policies issued by the province where the vehicle enterprises are located and the industrial support policies issued by the state. The monetary subsidy policy is not included in GI. FCF is measured by free cash flow/operating income. Free cash flow is calculated as follows (Lehn et al., 1989): operating profit before depreciation-total tax revenue-total interest- preferred stock dividend-common stock dividend. ALR is measured by asset liability ratio. ENERGY is measured by ratio of the total energy consumption of all driving mileage in the life cycle of annual sales vehicles converted into the quantity of standard coal and annual operating revenue. LSA is taken as the natural logarithm of total assets. Carbon emission performance (C\&P) of NEV enterprises was chosen as the explanatory variable.

\subsection{Method and data}

\subsubsection{Method}

In recent years, STIRPAT model developed from IPAT has been widely used in environmental research.

The specific forms are as follows:

$$
I_{i t}=a P_{i t}^{b} A_{i t}^{c} T_{i t}^{d} \varepsilon_{i t}
$$



technology; and $\varepsilon$ is residual regression term. To facilitate evaluate the importance of each factor, we take logarithm on both sides of the equation and convert it into a linear model:

$$
\ln \left(I_{i t}\right)=a+b \ln \left(P_{i t}\right)+\operatorname{cln}\left(A_{i t}\right)+d \ln \left(T_{i t}\right)+\varepsilon_{i t}
$$

STIRPAT model reflects the relationship between environment and influencing factors. This paper uses

The model is as follows:

$$
\ln \left(C \& P_{i t}\right)=\alpha_{0}+\alpha_{1} \ln \left(T I_{i t}\right)+\alpha_{2} \ln \left(G D_{i t}\right)+\alpha_{3} \ln \left(G I_{i t}\right)+\alpha_{4} \ln \left(F C F_{i t}\right)+\alpha_{5} \ln \left(A L R_{i t}\right)+
$$

$\alpha_{6} \ln \left(E N E R G Y_{i t}\right)+\alpha_{7} \ln \left(L S A_{i t}\right)+\varepsilon_{i t}$

Model (1)

In this part, we take the NEV enterprises selected in the previous paper as samples, and the interval is still

2011-2018. The data of explained variable C\&P comes from the calculation of SE-SBM model based on

unexpected output. The data of explanatory variables are from CSMAR database, Wilson Dashi database,

cninfo.com, annual reports of listed companies and official websites. Some missing data are sorted out

manually. The statistical software is stata2014.

\subsection{Empirical results and discussion}

Table 2 shows the empirical results of C\&P influencing factors in Chinese NEV enterprises.

The estimated coefficient of TI is 0.015713 , and the corresponding $\mathrm{p}$ value showed that the relationship

was significant at $1 \%$ level. This means that TI has a significant positive impact on C\&P of NEV enterprises.

That is, TI can promote performance improvement or carbon emission reduction. It is also possible that 
the great pressure of current carbon emission reduction targets, if the vehicle enterprise has a high level of TI, it

may carry out NEV R\&D project and is relatively successful, which is conducive to improving its $C \& P$.

The coefficients of GD and GI are 0.006851 and 0.000565 respectively, and their corresponding P values were significant at the level of 5\%. This shows that both GD and GI are significantly positively correlated with the C\&P of NEV enterprises. The GD coefficient is higher than the GI coefficient, which means that GD have a greater incentive effect on $\mathrm{C} \& \mathrm{P}$ of NEV enterprises. This is different from the conclusion of traditional mature industry. It is generally believed that in mature industries, the promotion effect of GI is better than that of GD. The reasons for this result may mainly come from the following two aspects: Firstly, the government indirect support policies are mostly ex post incentive, which requires enterprises to achieve certain goals before they can enjoy the preferential policies. Many R\&D projects of NEV manufacturers are still in the exploratory stage, which may not be successful. Even if they succeed, it will take time to translate into results. Therefore, the incentive effect of many indirect support policies on NEV enterprises lags behind, and the significance is bound to be poor. Secondly, as one of the emerging industries, the NEV industry is still in its infancy. Many projects need a lot of R\&D investment. The lack of cash support will make the NEV projects fail directly, which will have a great negative impact on the sustainable operation of enterprises. In order to carry out $R \& D$ smoothly, many enterprises need aid. However, since the NEV project should take into account the effect of environmental governance, the successful transformation of the achievements may not fully conform to the cost-effectiveness principle. It is difficult for NEV enterprises to obtain external funds, so the government must become a solid support for them. As an incentive in advance, financial and monetary subsidies can fill the gap of funds in time and solve the financing difficulties of NEV R\&D projects.

The variable coefficient of FCF is 0.000037 , which has passed the significance test. It shows that the FCF is significantly positively correlated with the C\&P of NEV enterprises. This may be because FCF represents an enterprise's ability to invest according to its own will. Cash is the basis for enterprises to continuously invest in 
NEV R\&D projects. If there is no sustained cash flow as support, there will be no NEV technology innovation, and the carbon emission governance project will be difficult to promote.

The coefficient of ALR is -0.000174 , which has passed the significance test of $5 \%$ level. It shows that the

370 ALR is negatively correlated with the C\&P of NEV enterprises. The existence of enterprise debt will have a negative impact on C\&P. With the increase of the proportion of debt, the negative impact will become more and more serious. May be the high risk and long payback period of NEV R\&D projects makes rational creditors unwilling to apply loans to such projects. The creditors even restricts the investment behavior of enterprises in NEV R\&D through contracts, which result in the significant constraint of debt on the enterprise's NEV R\&D activities. The reduction of $R \& D$ investment in low-carbon projects and the limitation of $R \& D$ activities will inevitably have adverse effects on C\&P. be seen that there is a significant negative correlation between $\mathrm{C} \& \mathrm{P}$ and vehicle energy consumption. The higher the ENERGY, the lower the C\&P. Enterprises should find ways to reduce vehicle energy consumption, including NEVs. Because NEVs in China mainly consume electricity. Most of the electric energy in China is thermal power generation. A certain amount of carbon emission will be produced in the process of power generation. Therefore, the higher the energy consumption, the more carbon emissions. When the energy consumption is reduced, the vehicle carbon emission will decrease with the decrease of energy consumption for the same mileage. Enterprises should try their best to reduce vehicle energy consumption to improve C\&P. scale of vehicle enterprises also has a negative impact on C\&P. This may be because larger enterprises mean more vehicle production. At this stage, NEVs have not yet occupied the dominant position in the vehicle industry. The increase in the total number of vehicles is likely to be caused by the increase in traditional vehicles, which has a negative impact on $C \& P$. 


\begin{tabular}{|c|c|c|c|c|c|c|}
\hline \multirow{2}{*}{ Variable } & \multicolumn{6}{|c|}{ Regression results } \\
\hline & Model（1） & Model（2） & Model（3） & Model（4） & Model（5） & Model（6） \\
\hline \multirow{2}{*}{$\operatorname{Ln}(\mathrm{TI})_{\mathrm{t}}$} & $0.015713^{* * *}$ & $0.013076^{* * *}$ & $0.014134^{* * * *}$ & $0.009330^{* * * *}$ & $0.013579^{* * * *}$ & $0.018543^{* * * *}$ \\
\hline & 0.001 & 0.001 & 0.007 & 0.000 & 0.003 & 0.006 \\
\hline \multirow{2}{*}{$\operatorname{Ln}(G D) t$} & $0.006851^{* * *}$ & $0.007961^{* * * *}$ & $0.001299^{* *}$ & $0.000893^{* * * *}$ & $0.006054^{* * * *}$ & $0.001678^{* *}$ \\
\hline & 0.000 & 0.003 & 0.037 & 0.000 & 0.001 & 0.044 \\
\hline \multirow{2}{*}{$\operatorname{Ln}(\mathrm{GI})_{\mathrm{t}}$} & $0.000565^{* *}$ & $0.000931^{* * * *}$ & $0.000194^{* *}$ & $0.000479^{* * *}$ & $0.000764^{* *}$ & $0.000931^{* *}$ \\
\hline & 0.030 & 0.003 & 0.034 & 0.016 & 0.036 & 0.049 \\
\hline \multirow{2}{*}{$\operatorname{Ln}(\mathrm{FCF})_{\mathrm{t}}$} & $0.000037^{*}$ & $0.000173^{* *}$ & $0.000859^{*}$ & $0.000365^{* *}$ & $0.0006089^{* *}$ & $0.000986^{* *}$ \\
\hline & 0.073 & 0.029 & 0.066 & 0.017 & 0.026 & 0.031 \\
\hline \multirow{2}{*}{$\operatorname{Ln}(\mathrm{ALR})_{\mathrm{t}}$} & $-0.000174^{* *}$ & $-0.000567^{* * *}$ & $-0.000221^{* *}$ & $-0.000263^{* *}$ & $-0.000983^{*}$ & $-0.000571^{* * *}$ \\
\hline & 0.017 & 0.007 & 0.031 & 0.015 & 0.071 & 0.001 \\
\hline \multirow{2}{*}{$\operatorname{Ln}(\mathrm{ENERGY}) \mathrm{t}$} & $-0.013198^{* * * *}$ & $-0.076063^{* *}$ & $-0.001328^{* * * *}$ & $-0.000940^{* * * *}$ & $-0.035809^{* * * *}$ & $-0.079433^{* * *}$ \\
\hline & 0.005 & 0.015 & 0.004 & 0.007 & 0.005 & 0.005 \\
\hline \multirow{2}{*}{$\operatorname{Ln}(\mathrm{LSA})_{\mathrm{t}}$} & $-0.008979^{*}$ & $-0.011075^{* *}$ & $-0.017367^{* *}$ & $-0.008156^{*}$ & $-0.009054^{*}$ & $-0.007631^{* *}$ \\
\hline & 0.091 & 0.018 & 0.033 & 0.068 & 0.086 & 0.041 \\
\hline
\end{tabular}

Note: ${ }^{* * *},{ }^{* *}$ and ${ }^{*}$ are significant at $1 \%, 5 \%$, and $10 \%$ levels, respectively

\subsection{Robustness test}

According to the regression results, TI, G, FCF, ALR, ENERGY, LSA are significantly correlated with

NEV enterprise C\&P. In order to verify the robustness of the results, we use the permutation variable method

to test the regression results again. The calculation method of five variables except ENERGY was changed. TI is measured by the ratio of patents to R\&D investment. GD is calculated by the ratio of government subsidies to total assets. ALR is measured by the proportion of current liabilities and noncurrent liabilities. LSA is measured by the logarithm of operating revenue. FCF is measured as the ratio of free cash flow to total assets. Models (2)-(6) replace TI, GD, FCF, ALR and LSA on the basis of model (1). There was no significant change in the results.

\subsection{Further discussion}

NEV is the best choice for low-carbon development of vehicle industry (DeLuehi et al., 1989; Doucette, 2011; Delucchi et al., 2014). However, from the research results of this paper, the current NEV enterprise C\&P is not ideal. It is necessary to further adjust the strategy to improve the C\&P of NEV enterprises. According to the empirical results, TI, G and FCF are directly proportional to C\&P of NEV enterprises, while ALR, 
ENERGY and LSA are inversely proportional to C\&P of NEV enterprises. This means that in order to improve technological innovation, enterprise governance structure and vehicle energy consumption (Velte et al., 2020;

Trinks, 2020). development(Sovacoola et al., 2019; Meelen et al., 2019; Wesseling et al., 2014). Moreover, TI is related to all the factors discussed in this paper (Fig. 5). It is the key factor that we have to consider to improve the C\&P of NEV enterprises. Firstly, TI can improve the relationship between LSA and C\&P. NEV production needs to cross the technical threshold. The solution of core technical problems can help NEV to gain consumer recognition. If these conditions are met, NEV may be sold on a large scale (Wu et al., 2020). In this case, with the pressure of environmental protection, large-scale enterprises are more inclined to produce NEV instead of traditional vehicles. Coupled with the support of the government, enterprises can make more profits from NEV sales. C\&P will be improved. The negative effect of LSA on C\&P decreases or even turns into positive effect. Secondly, TI can improve the relationship between ENERGY and C\&P. At present, NEV in China mainly consumes electric energy. Most of China's electricity is obtained by burning coal. Coal produces $\mathrm{co}_{2}$ during combustion. The results show that ENERGY has the greatest negative impact on C\&P of NEV enterprises. Therefore, it is necessary to reduce the energy consumption of NEV. TI can achieve this goal (Ambrose et al., 2020; Ehrenberger et al., 2020). Thirdly, the effect of TI is related to NEV's enterprise governance structure and its initiative for R\&D activities (Liu et al., 2018). If NEV enterprises reduce the proportion of restricted liabilities appropriately, hold a certain amount of cash flow, increase R\&D funds and personnel input, the development and transformation speed of technological achievements will be improved. The transformation of scientific and technological achievements into the core competitiveness of enterprises as soon as possible will 

capital investment will either produce huge benefits or be subject to mandatory policies. At present, it is difficult for NEVs to generate stable revenue, let alone huge revenue. In addition, the TI of NEV needs huge capital, which is difficult for enterprises to meet on their own. Therefore, TI needs the support and supervision of the government. In order to impel NEV enterprises carry out technological innovation activities, the government should take the following measures. The first measure is to improve the financial support policies for the NEV industry, solving the problem of fund sources for NEV enterprises through market forces. The second measure is to promote the initiative of enterprises through administrative means. According to the existing research, enterprises with good technological innovation achievements attach great importance to technological innovation. Generally, in such enterprises, innovation investment is relatively active, the corresponding system is relatively perfect, and the efforts of R\&D personnel are relatively high (Liu et al., achievements.

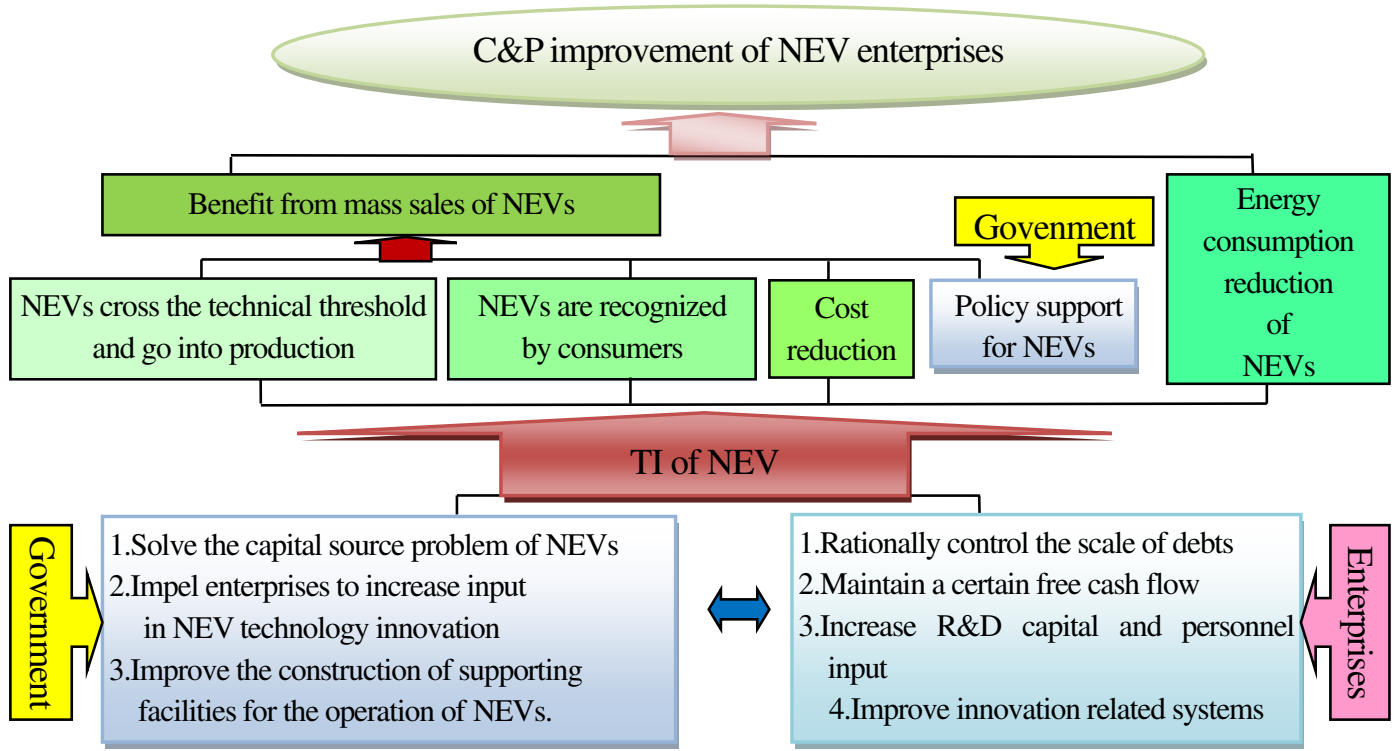

Fig.5 Influence mechanism of influencing factors on C\&P of NEV enterprises 
As one of the important means of vehicle exhaust governance, the development of NEVs has attracted

much attention. In order to promote the development of NEV industry and achieve the goal of low-carbon economic development of the vehicle industry, the Chinese government has issued a number of supporting policies. The early policy mainly focused on financial subsidies, which contributed a lot to the initial formation of the NEV market. The loose subsidy policy reduces the industrial threshold. A lot of capital, enterprises and technologies are pouring into the NEV industry. The industry is booming. In this case, the number of NEVs in China is increasing rapidly with an average annual growth rate of $40 \%$. The NEV industry has achieved the government's "preliminary new energy" strategic goal. With the rapid development of NEV industry, the disadvantages of subsidy are gradually emerging. The frequent occurrence of "cheating compensation" events of NEVs is the concentrated embodiment of this kind of malpractice. In order to improve this situation, Chinese government has adjusted the promotion policy of NEVs. They raised the industry access threshold to encourage the popularization and application of high energy density and low energy consumption vehicles. The announcement of double points policy makes many NEV enterprises eliminated. The small and inferior enterprises are gradually out of the competition, while the excellent enterprises continue to improve their technical level to cope with the increasing industrial access threshold. The implementation and adjustment of a series of policies issued by the government are all aimed at truly achieving the goal of coordinated development of environmental governance and vehicle industry. However, the realization of this goal depends on the behavior of enterprises as the main body of the vehicle industry. At the time of further promoting the in-depth development of NEVs, it is of practical significance to evaluate the carbon emission performance of NEV enterprises and study the influencing factors. The finding of calculating the carbon emission performance 

also distinct. On the basis of evaluating the carbon emission performance of NEV enterprises, this paper constructs an extended STIRPAT model to analyze the influencing factors. The results show that the carbon emission performance of NEV is positively correlated with technological innovation, government support, free cash flow, and negatively correlated with debt constraint, energy intensity, enterprise size.

\section{Data availability}

475 Not applicable.

\section{$476 \quad$ Reference}

Ambrose H, Kendall A, Lozano M, Wachche S, Fulton L. Trends in life cycle greenhouse gas emissions of future light duty electric vehicles. Transportation Research Part D: Transport and environment 2020; 81 :

Ayetor GK, Quansah DA, Adjei EA. Towards zero vehicle emissions in Africa: A case study of Ghana. Energy Policy 2020; 143: 111606.

Bank TW. The China new energy vehicles program: challenges and opportunities. 2011.

Bonsu NO. Towards a circular and low-carbon economy: Insights from the transitioning to electric vehicles and net zero economy. Journal of Cleaner Production 2020; 256: 120659.

Braune E, Sahut JM, Teulon F. Intangible capital, governance and financial performance. Technological Forecasting and Social Change 2020; 154: 119934.

Cecchini L, Venanzi S, Pierri A, Chiorri M. Environmental efficiency analysis and estimation of $\mathrm{CO}_{2}$ abatement costs in dairy cattle farms in Umbria (Italy): A SBM-DEA model with undesirable output. Journal of Cleaner Production 2018; 197: 895-907. 
Chang L, Hao X, Song M, Wu J, Feng Y, Qiao Y, Zhang B. Carbon emission performance and quota allocation in the Bohai Rim Economic Circle. Journal of Cleaner Production 2020; 258: 120722.

Chang YT, Park H, Jeong J, Lee J. Evaluating economic and environmental efficiency of global airlines: A SBM-DEA approach. Transportation Research Part D: Transport and Environment 2014; 27: 46-50.

Choi W, Yoo E, Seol E, Kim M, Song HH. Greenhouse gas emissions of conventional and alternative vehicles: Predictions based on energy policy analysis in South Korea. Applied Energy 2020; 265: 114754.

Cui Y, Khan SU, Li Z, Zhao M. Environmental effect, price subsidy and financial performance: Evidence from Chinese new energy enterprises. Energy Policy 2021; 149: 112050.

Delucchi MA, Yang C, Burke AF, Ogden JM, Kurani K, Kessler J, Sperling D. An assessment of electric vehicles: technology, infrastructure requirements, greenhouse-gas emissions, petroleum use, material use, lifetime cost, consumer acceptance and policy initiatives. Philosophical Transactions of the Royal Society A-Mathematical Physical and Engineering Sciences 2014; 372(2006): 20120325. https://doi.org/10.1098/rsta.2012.0325.

DeLuehi M, Wang Q, Sperling D. Electronic vehicles: performances, life-cycle costs, emissions, and recharging requirements. TransportationResearch PartA: General 1989; 23(3): 255-278.

Ding L, Yang Y, Wang W, Calin AC. Regional carbon emission efficiency and its dynamic evolution in China: A novel cross efficiency-malmquist productivity index. Journal of Cleaner Production 2019; 241: 118260.

Doucette RT, McCulloch MD. Modeling the prospects of plug-in hybrid electric vehicles to reduce $\mathrm{CO}_{2}$ emissions. Applied Energy 2011; 88: 2315-2323.

Ehrenberger SI, Konrad M, Philipps F. Pollutant emissions analysis of three plug-in hybrid electric vehicles using different modes of operation and driving conditions. Atmospheric Environment 2020; 234: 117612.

Elshurafa AM, Peerbocus N. Electric vehicle deployment and carbon emissions in Saudi Arabia: A power 
system perspective. The Electricity Journal 2020; 33(6): 106774.

516 Feng S. The technology convergence of electric vehicles: Exploring promising and potential technology convergence relationships and topics. Journal of Cleaner Production 2020; 260: 120992.

Glitman K, Farnsworth D, Hildermeier J. The role of electric vehicles in a decarbonized economy: supporting a reliable, affordable and efficient electric system. The Electricity Journal 2019; 32 (7): 106623.

Gohoungodji P, N'Dri AB, Latulippe J, Matos ALB. What is stopping the automotive industry from going green? A systematic review of barriers to green innovation in the automotive industry. Journal of Cleaner

Guo XD, Zhu L, Fan Y, Xie BC. Evaluation of potential reductions in carbon emissions in Chinese provinces Production 2020; 277: 123524.

Han X, Cao T, Sun T. Analysis on the variation rule and influencing factors of energy consumption carbon emission intensity in China's urbanization construction. Journal of Cleaner Production 2019; $238: 117958$.

based on environmental DEA. Energy Policy 2011; 39(5): 2352-2360.

Iftikhar Y, Wang Z, Zhang B, Wang B. Energy and $\mathrm{CO}_{2}$ emissions efficiency of major economies: A network DEA approach. Energy 2018; 147: 197-207.

IPCC. IPCC Guidelines for National Greenhouse Gas Inventories. Global Environmental Strategy Institute. Japan 2006.

Jenn A, Springel K, Gopal AR. Effectiveness of electric vehicle incentives in the United States. Energy Policy 2018; 119: 349-356.

Juan Z. R\&D for Environmental Innovation and Supportive Policy: The Implications for New Energy Automobile Industry in China. Energy Procedia 2011; 5(none): 1003-1007.

Kang CC, Khan AH, Feng CM, Wu CC. Efficiency evaluation of bus transit firms with and without consideration of environmental air-pollution emissions. Transportation Research Part D: Transport and Environment 2016; 50: 505-519. 
Lehn K, Poulson A. Free cash flow and stockholder gains in going private transactions. The Journal of Finance 1989; 44(3): 771-787. DOI:10.1111/j.1540-6261.1989.tb04390.x

Li J. Charging Chinese future: the roadmap of China's policy for new energy automotive industry. Science Direct 2020; 45(20): 11409-11423.

Li N, Chen J, Tsai I, He Q, Chi S, Lin Y, Fu T. Potential impacts of electric vehicles on air quality in Taiwan. Science of The Total Environment 2016; 566: 919-928.

Li W, Wang W, Qin Y. Evaluation of regional metafrontier total factor carbon emission performance in China's construction industry: Analysis based on modified non-radial directional distance function. Journal of Cleaner Production 2020; 256: 120425.

Lin X, Zhu X, Han Y, Geng Z, Liu L. Economy and carbon dioxide emissions effects of energy structures in the world: Evidence based on SBM-DEA model. Science of The Total Environment 2020; 729: 138947.

Liu L, Zhang T, Avrin AP, Wang X. Is China's industrial policy effective? An empirical study of the new energy vehicles industry. Technology in Society 2020; 63: 101356.

Liu Z, Mu R, Hu S, Wang L, Wang S. Intellectual property protection, technological innovation and enterprise value: An empirical study on panel data of 80 advanced manufacturing SMEs. Cognitive Systems Research 2018; 52: 741-746.

Lucas A, Silva CA, Neto RC. Life cycle analysis of energy supply infrastructure for conventional and electric vehicles. Energy Policy 2012; 41(2): 537-547.

Meelen T, Truffer B, Schwanen T. Virtual user communities contributing to upscaling innovations in transitions: The case of electric vehicles. Environmental Innovation and Societal Transitions 2019; 31: 96-109.

Rehermanna F, Pablo-Romero M. Economic growth and transport energy consumption in the Latin American and Caribbean countries. Energy Policy 2018; 122: 518-527.

Reinhard S, Lovell CAK, Thijssen GJ. Environmental efficiency with multiple environmentally detrimental 
variables; estimated with SFA and DEA. European Journal of Operational Research 2000; 121(2): 287-303.

Ren J. New energy vehicle in China for sustainable development: Analysis of success factors and strategic implications. Transportation Research Part D: Transport and environment 2018; 59: 268-288.

Shaheen S, Martin E, Totte H. Zero-emission vehicle exposure within U.S. carsharing fleets and impacts on sentiment toward electric-drive vehicles. Transport Policy 2019; 85: A23-A32.

Shuai S, Fan Z. Modeling the role of environmental regulations in regional green economy efficiency of China: Research 2001; 130(3): 498-509. 
Tone K, Sahoo BK. Degree of scale economies and congestion: A unified DEA approach. European Journal of Operational Research 2004; 158(3): 755-772.

Trinks A, Mulder M, Scholtens B. An Efficiency Perspective on Carbon Emissions and Financial Performance. Ecological Economics 2020; 175: 106632.

Velte P, Stawinoga M, Lueg R. Carbon performance and disclosure: A systematic review of governance-related determinants and financial consequences. Journal of Cleaner Production $\quad 2020 ; 254: 120063$.

Wang C, Zhan J, Zhang F. Measuring carbon emission performance of industrial sectors in the Beijing-Tianjin-Hebei region, China: A stochastic frontier approach. Science of The Total Environment

Wang Q, Zhao C. Regional difference and driving factors of industrial carbon emissions performance in China. Alexandria Engineering Journal 2020; 60(1): 301-309.

Wang Z, Xu X, Zhu Y, Gan T. Evaluation of carbon emission efficiency in China's airlines. Journal of Cleaner Production 2019; 243: 118500. 105578.

601

Wanga KL, Miao Z, Zhao MS, Miao CL, Wang QW. China's provincial total-factor air pollution emission efficiency evaluation, dynamic evolution and influencing factors. Ecological Indicators 2019; 107:

Wu F, Zhou P, Zhou DQ. Modeling carbon emission performance under a new joint production technology with energy input. Energy Economics 2020; 92: 104963. strategy in new energy vehicle industry: Evidence from listed companies in China. Journal of Cleaner 
Wu YA, Ng AW, Yu Z, Huang J, Meng K, Dong ZY. A review of evolutionary policy incentives for sustainable development of electric vehicles in China: Strategic implications. Energy Policy 2021; 148: 111983.

Yan D, Lei Y, Li L, Song W. Carbon emission efficiency and spatial clustering analyses in China's thermal power industry: Evidence from the provincial level. Journal of Cleaner Production 2017; 156: 518-527.

Yang J, Tang L, Mi Z, Liu S, Li L, Zheng J. Carbon emissions performance in logistics at the city level. Journal of Cleaner Production 2019; 231: 1258-1266.

Zhai H, Frey HC, Rouphail NM. Development of a modal emissions model for a hybrid electric vehicle. Transportation Research Part D: Transport and environment 2011; 16: 444-450.

Zhou Y, Liu W, Lv X, Chen X, Shen M. Investigating interior driving factors and cross-industrial linkages of carbon emission efficiency in China's construction industry: Based on Super-SBM DEA and GVAR model. Journal of Cleaner Production 2019; 241: 118322.

\section{Acknowledgements}

The authors would like to thank the National Office for Philosophy and Social Sciences of China for providing funding. This work was supported by the National Social Science Foundation of China.

\section{Funding}

623 This work has received funding from the general project of national social science foundation of China:

624 "Research on mechanism and supportive polices of environmental pollution cooperative governance in the 625 process of regional integration development of the Yangtze River delta" (Approval number: 19BJL035).

\section{Author information}

627 Affiliations

628 Min Zhao, Collage of Economics and Management, Nanjing University of Aeronautics and Astronautics, Nanjing, 21106, China

Tao Sun, Collage of Economics and Management, Nanjing University of Aeronautics and Astronautics, Nanjing, 21106, China 
630 Qiang Feng, Collage of Economics and Management, Nanjing University of Aeronautics and Astronautics, Nanjing, 21106, China

631 Author's contribution

632 This paper was completed by three authors. Dr. Min Zhao designed and wrote the first draft of the paper. She

633 was the major contributor in writing the manuscript. Professor Tao Sun revised the manuscript. Dr. Qiang Feng

634 participated in the research and carried out the research data investigation. Authors are ranked by contribution.

635 Corresponding author, Tao Sun, 13951941170, nuaastao@163.com.

636 Ethics declarations

637 Competing interests

638 The authors declare that they have no competing interests.

639 Ethics approval and consent to participate

$640 \quad$ Not Applicable

641 Consent to Publish

642 Not Applicable.

643 Availability of data and materials

644 Not Applicable 


\section{Figures}

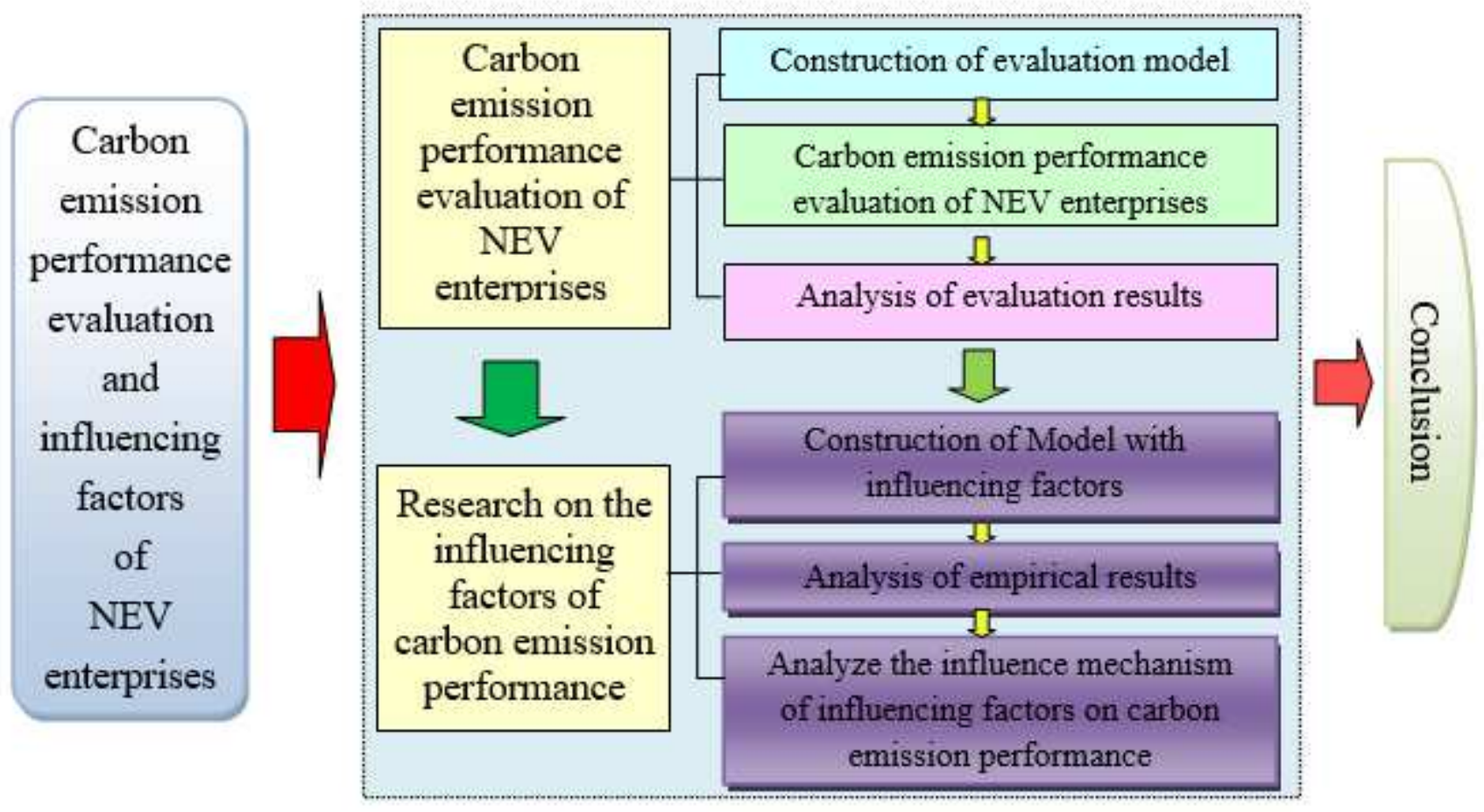

\section{Figure 1}

Research framework

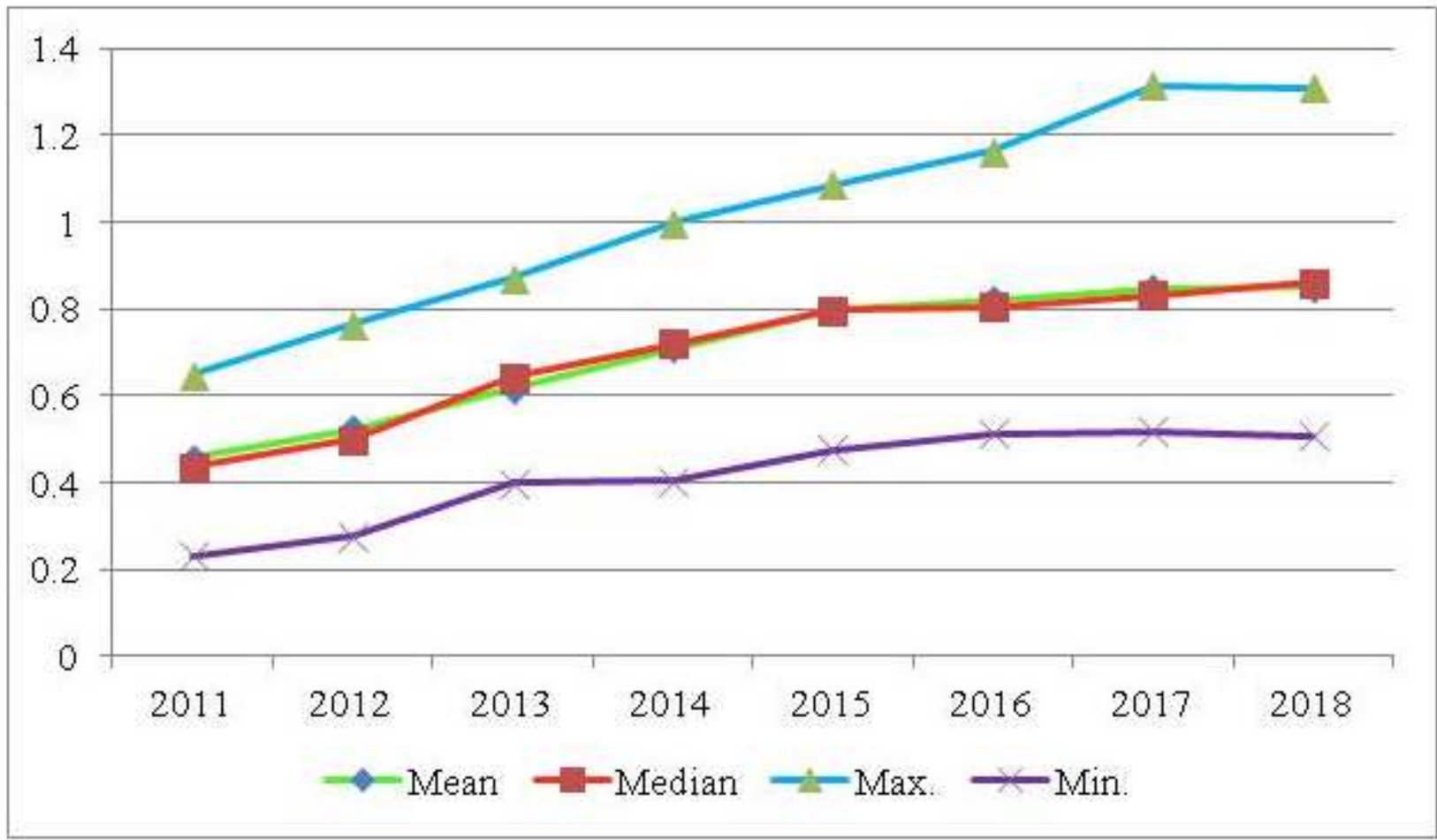


Figure 2

Carbon emission performance(C\&P) trends of NEV enterprises from 2011 to 2018

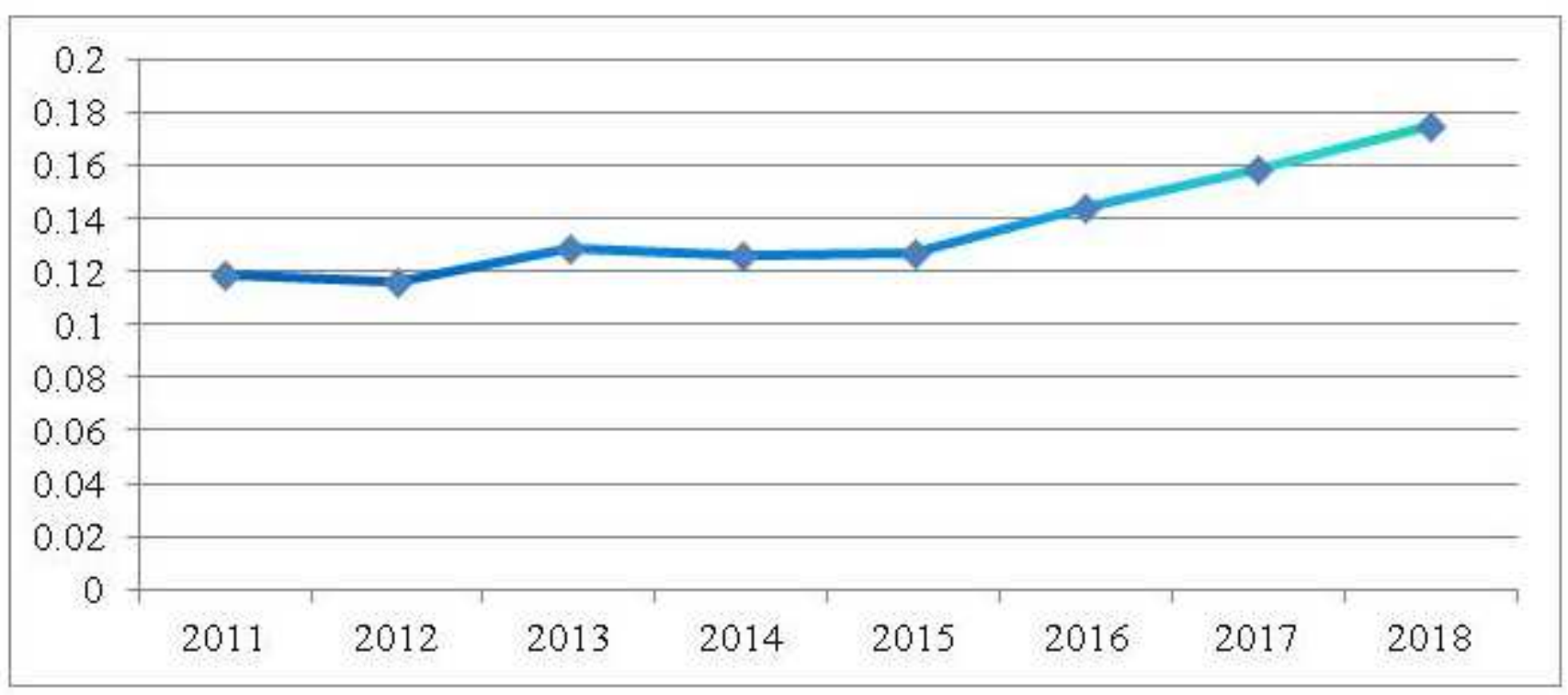

Figure 3

Trend of C\&P Std. between NEV enterprises from 2011 to 2018 


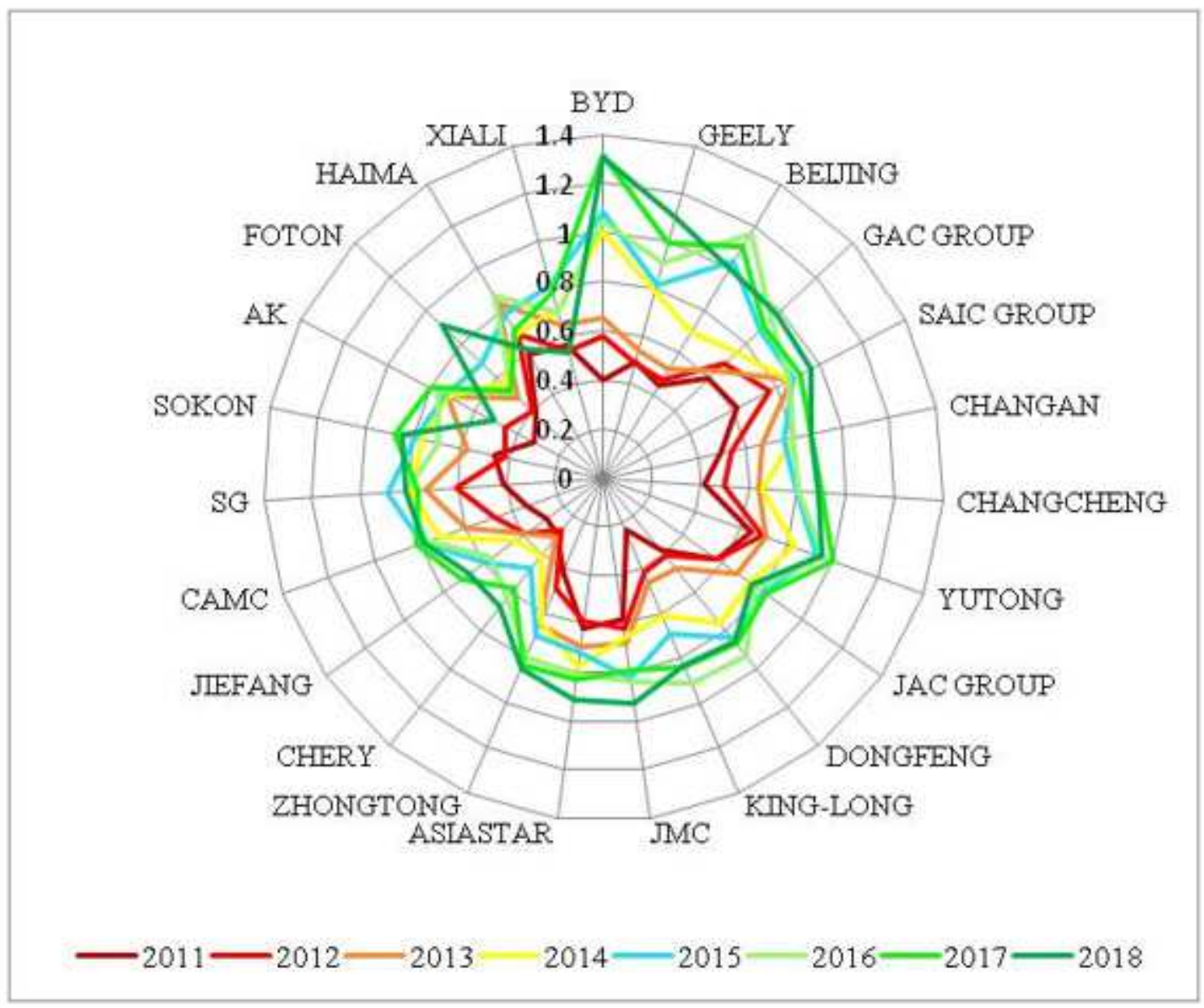

Figure 4

C\&P of NEV enterprises from 2011 to 2018 


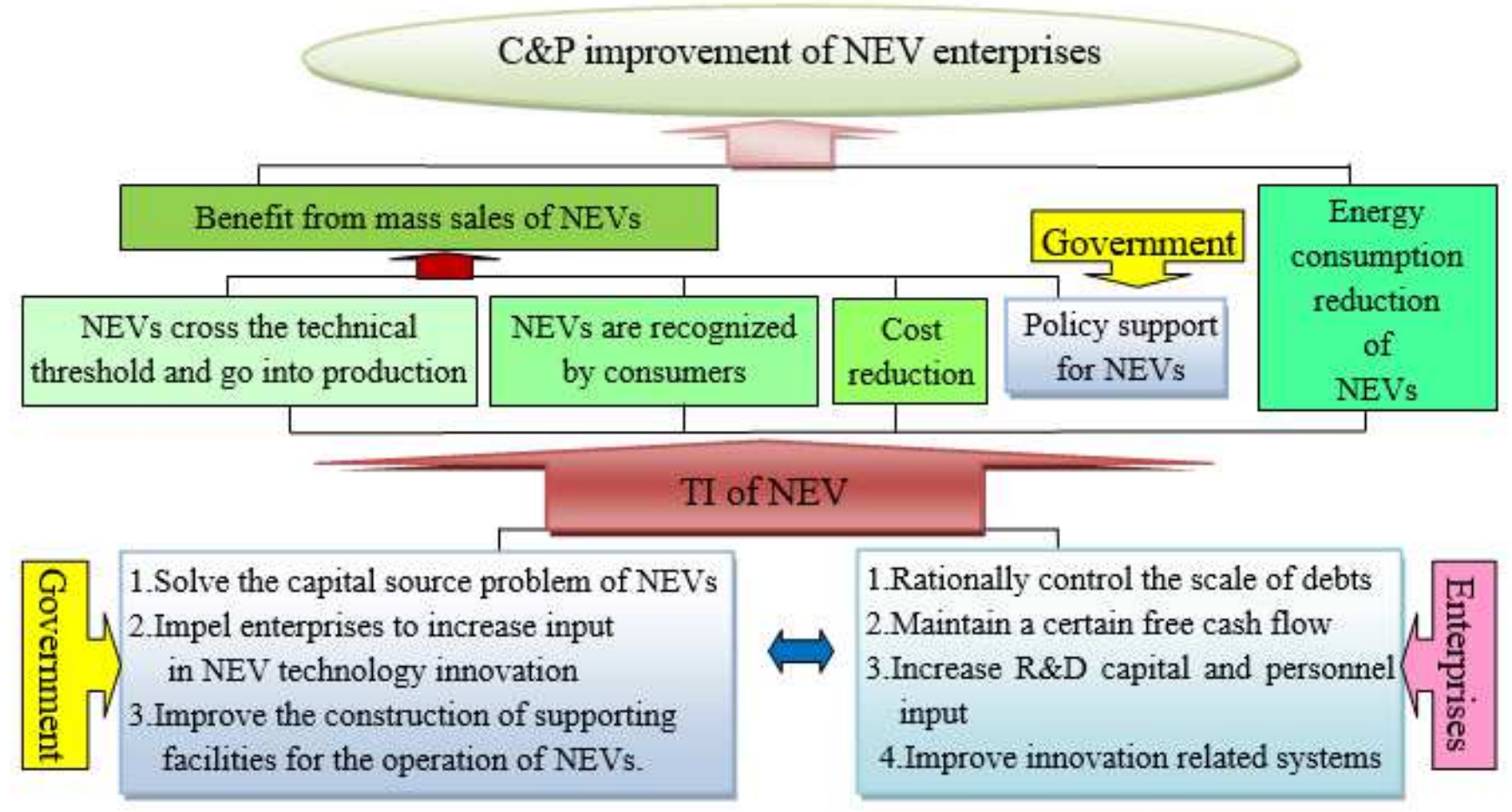

Figure 5

Influence mechanism of influencing factors on C\&P of NEV enterprises 